\title{
A avaliação não é $100 \%$ justa! Representações sobre a avaliação de desempenho num estudo de caso
}

\author{
The evaluation is not $100 \%$ fair! Representations about the performance \\ evaluation on a case study
}

Daniela Silva, Ana Barbosa

Universidade do Minho

\begin{abstract}
Resumen
Esta comunicação apresenta um estudo sobre as representações das educadoras de infância e ajudantes de ação educativa, numa organização do terceiro setor, na valência de creche e jardim de infância. Os objetivos desta comunicação visam: i) conhecer e compreender as representações sobre a avaliação de desempenho dos educadores de infância e ajudantes de ação educativa na valência da creche e jardim de infância; ii) identificar potencialidades e constrangimentos desta prática de recursos humanos. A metodologia de investigação baseouse num estudo de caso e a técnica foi o focus-group, aplicado a educadoras de infância, ajudantes de ação educativa.

Palavras chave: avaliação de desempenho, recursos humanos, organizações
\end{abstract}

\begin{abstract}
This paper presents a study on the representations of the educators of childhood, in a third sector organization, in the valency of kindergarten. The aims of this communication are: i) to know and understand the representations about the performance evaluation of the educators of childhood in the valency of kindergarten; ii) identify potentialities and constraints of this practice of human resources. The research methodology was based on a case study and the technique was the focus group, applied to educators of childhood.

Keywords: Performance evaluation, human resources,organizations
\end{abstract}

\section{Introdução}

Hodiernamente, vivemos numa sociedade global marcada por paradoxos que oscilam entre as demandas da construção da sociedade democrática e as exigências do mercado neoliberal. Nestas tensões, a sociedade cria mecanismos de regulação nomeadamente a avaliação, de tal modo que as práticas de avaliação passam a fazer parte do nosso quotidiano social e das políticas e práticas de recursos humanos das organizações. No contexto das organizações, muitas introduziram mecanismos de avaliação que as tornam mais eficazes e competitivas no mercado. O investimento no capital humano leva a que se desenvolvam práticas de avaliação de desempenho dos recursos humanos como instrumento de regulação dos desempenhos individuais, grupais e da própria organização e que garantam a sua qualidade no mercado. Todavia, o modo como os mecanismos de avaliação são apropriados pelos dirigentes organizacionais varia consoante a natureza das organizações.

A avaliação de desempenho representa nos dias de hoje uma área central da gestão de recursos humanos. Presente no Código de trabalho e instituida desde 2007 no ámbito da administração pública através do Sistema Integrado de Gestão e Avaliação do Desempenho na Administração Pública (SIADAP), a avaliação de desempenho pode assumir varios papéis no ámbito das relações laborais, desde uma dimensão formativa até uma dimensão mais punitiva como se encontra patente atualmente na sexta alteração ao Código de Trabalho (Lei n..$^{\circ}$ 27/2014 de 8 de maio) que determina como primeiro critério, em situações de extinção do posto de trabalho: "para determinação do posto de trabalho a extinguir, a decisão do empregador deve observar, por referência aos respetivos titulares, a seguinte ordem de critérios relevantes e não discriminatórios: a) Pior avaliação de desempenho, com parâmetros previamente conhecidos pelo trabalhador" (art. 368..$^{\circ}$ n. ${ }^{\circ}$ 2, Lei n. ${ }^{\circ}$ 27/2014). Neste sentido, a legislação que vigora atualmente, em Portugal, considera a avaliação de desempenho como um dos critérios a ter em consideração aquando a determinação do posto de trabalho a extinguir no regime do despedimento por extinção de posto de trabalho. A avaliação de desempenho é uma prática de recursos humanos que se encontra presente em muitas organizações, com finalidades diferentes da presente lei.

Para além da função pública, outros organismos privados e do terceiro sector, começaram nos últimos a conceber práticas de avaliação de desempenho, sendo que esta representa uma das políticas de aplicação dos recursos humanos. Esta comunicação debruça-se sobre esta temática e apresenta um estudo sobre as representações das educadoras de infância e ajudantes de ação educativa, numa organização do terceiro setor, situada na região do Minho, na valência de creche e jardim de infância, que se desenvolveu no ano de 2016. Os objetivos desta comunicação visam: i) conhecer e compreender as representações sobre a avaliação de desempenho dos educadores de infância e ajudantes de 
ação educativa na valência da creche e jardim de infância; ii) identificar potencialidades e constrangimentos desta prática de recursos humanos e iii) refletir sobre as diferentes formas de apropriação da avaliação de desempenho por parte destes atores organizacionais. A metodologia de investigação adotada baseia-se no paradigma qualitativo, desenvolvida através do método do estudo de caso. A técnica de recolha de dados selecionada foi o focus-group, aplicado a dois grupos constituídos por educadoras de infância, ajudantes de ação educativa e trabalhadoras dos serviços gerais do estudo de caso.

\section{A avaliação de desempenho - dimensões concetuais}

Em Portugal, um dos exemplos da introdução de mecanismos de avaliação é a instituição do Sistema Integrado de Gestão e Avaliação do Desempenho na Administração Pública (SIADAP) que constituiu um importante marco na história de processos avaliativos. Este é um sistema de avaliação de desempenho dos trabalhadores de organismos e instituições do setor público. A implementação desde sistema tem por base a Lei n. ${ }^{\circ}$ 66-B/2007 de 28 de dezembro que estabelece como objetivos:

“a) Contribuir para a melhoria da gestão da Administração Pública em razão das necessidades dos utilizadores e alinhar a actividade dos serviços com os objectivos das políticas públicas;

b) Desenvolver e consolidar práticas de avaliação e auto-regulação da Administração Pública;

c) Identificar as necessidades de formação e desenvolvimento profissional adequadas à melhoria do desempenho dos serviços, dos dirigentes e dos trabalhadores;

d) Promover a motivação e o desenvolvimento das competências e qualificações dos dirigentes e trabalhadores, favorecendo a formação ao longo da vida;

e) Reconhecer e distinguir serviços, dirigentes e trabalhadores pelo seu desempenho e pelos resultados obtidos e estimulando o desenvolvimento de uma cultura de excelência e qualidade;

f) Melhorar a arquitectura de processos, gerando valor acrescentado para os utilizadores, numa óptica de tempo, custo e qualidade;

g) Melhorar a prestação de informação e a transparência da acção dos serviços da Administração Pública;

h) Apoiar o processo de decisões estratégicas através de informação relativa a resultados e custos, designadamente em matéria de pertinência da existência de serviços, das suas atribuições, organização e actividades" (art. 6 , Lei n. $^{\circ}$ 66-B/2007).

Ainda que o SIADAP vigore, atualmente, somente na função pública, este apresenta-se como um contributo importante para outras organizações sejam privadas ou do terceiro setor, sendo que, no presente caso, este "visa contribuir para a melhoria do desempenho e qualidade de serviço da Administração Pública, para a coerência e harmonia da ação dos serviços, dirigentes e demais trabalhadores e para a promoção da sua motivação profissional e desenvolvimento de competências" (art. $1^{\circ}$, Lei n. ${ }^{\circ}$ 66-B/2007).
Os papéis atribuidos à avaliação de desempenho no SIADAP inscrevem-se numa linha de aperfeiçoamento e menhoria dos desempenhos invididuais e, por consequência, no desenvolvimento organizacional, caminando num sentido inverso ao do Código do Trabalho.

Emergente, sobretudo, nos anos 80, numa fase em que os recursos humanos se assumem como um factor estratégico das organizações (cf. Brandão \& Parente, 1998), a avaliação de desempenho consagra-se como "um método que visa estabelecer um acordo com os funcionários, de forma contínua, de acordo com os resultados esperados pela organização, acompanhar os desafios, corrigindo os rumos, quando necessário, e avaliar o desempenho" (Pontes, 1999:24). Nesta acepção, a avaliação de desempenho pode ser entendida como uma forma de aproximar as motivações dos trabalhadores às da organização partilhando objetivos comuns e dispondo de um acompanhamento como forma de aperfeiçoar e melhorar as práticas quer do trabalhador, quer da própria organização. Na mesma linha de pensamento, C. LevyLeboyer (1991:93) considera que a avaliação "implica tanto o indivíduo como a organização, porque é necessário, simultaneamente, que os responsáveis pela decisão, no seio da organização, avaliem o indivíduo, e que este colabore para si próprio uma imagem completa do que a organização espera dele e do que ele pode, por sua vez, esperar da organização". Neste sentido, "a motivação dos indivíduos para o trabalho não se mede como uma característica individual: constrói-se" (1991:94). Este carácter construtivista é apoiado, na linha de pensamento do autor, na teoria da instrumentalidade para fundamentar a ideia de que "nenhum trabalhador será motivado se não se aperceber claramente da maneira como estão ligados o seu trabalho e o que a organização lhe dá em troca" (ibidem). Deste modo, "as avaliações recebidas, de maneira formal ou informal, da parte dos outros [...] nunca são um processo neutro aos olhos desse alguém" (ibidem), sendo imperativo clarificar e desmistificar os modos como são conduzidos os momentos e os procesos de avaliação de desempenho para que, o individuo que está a ser avaliado tenha conhecimento, com clareza, dos parâmetros de avaliação a que está sujeito.

No ámbito das políticas de recursos humanos, a avaliação de desempenho não se encontra isolada das outras políticas mas representa um processo importante para o cumprimento de várias finalidades da gestão de recursos humanos.

A implementação de um dispositivo de avaliação de desempenho contempla vários benefícios para o trabalhador, para a direção e para a organização, como nos relata I. Chiavenato. De entre os beneficios, I. Chiavenato refere que o trabalhador:

- "fica conhecendo as regras do jogo, ou seja, os aspectos de comportamento e de desempenho que a empresa mais valoriza em seus funcionários;

- fica conhecendo quais as expectativas de seu chefe a respeito do seu desempenho e seus pontos fortes e fracos, segundo a avaliação do chefe; 
- fica sabendo quais as providências que o chefe está tomando quanto à melhoria de seu desempenho (programas de treinamento, estágios etc.) e as que ele próprio - subordinado - deverá tomar por conta própria (autocorreção, maior capricho, mais atenção no trabalho, cursos por conta própria etc.) ; e

- tem condições para fazer a auto-avaliação e autocrítica para o seu autodesenvolvimento e autocontrole" (1989:92).

Os benefícios para a direção estão relacionados com o facto de "ter condições para:

- melhor avaliar o desempenho e o comportamento dos subordinados, tendo por base variáveis e fatores de avaliação e, principalmente, contando com um sistema de medição capaz de neutralizar a subjetividade;

- propor medidas e providências no sentido de melhorar o padrão de comportamento de seus subordinados; e

- comunicar-se com os seus subordinados, no sentido de fazê-los compreender a mecânica da avaliação do desempenho como um sistema objetivo e como está desenvolvendo-se seu desempenho, através desse sistema" (ibidem).

No que concerne aos benefícios para a organização, o autor destaca essencialmente três:

- "tem condições de avaliar seu potencial humano a curto, médio e longo prazos e definir a contribuição de cada empregado;

- pode identificar os empregados que necessitam de reciclagem e/ou aperfeiçoamento em determinadas áreas de atividade e selecionar os empregados com condições de promoção ou transferências; e

- pode dinamizar sua política de recursos humanos, oferecendo oportunidades aos empregados (não só de promoções, mas principalmente de crescimento e desenvolvimento pessoal), estimulando a produtividade e melhorando o relacionamento humano no trabalho" (ibidem).

Em síntese, a avaliação de desempenho constitui um importante processo para o desenvolvimento de certas práticas de recursos humanos, acarreta contributos favoráveis para o trabalhador, para a direção e para a organização.

\section{Notas metodológicas}

O paradigma de investigação adotado neste estudo foi o paradigma qualitativo na medida em que privilegia a interpretação, compreensão, intersubjetividade e diálogo. De acordo com as caraterísticas do paradigma qualitativo, o desenvolvimento desta dimensão implica "uma partilha densa com pessoas, fatos e locais que constituem objetos de pesquisa, para extrair desse convívio os significados visíveis e latentes que somente são perceptíveis a uma atenção sensível" (Chizzotti, 2001) privilegiando a busca pela descrição, interpretação e compreensão da realidade, valorizando a dimensão subjetiva da mesma. Nesta linha de ideias procuramos explorar e compreender quais as representações dos trabalhadores do estudo de caso (método) acerca da avaliação de desempenho, do seu trabalho e das suas funções, auscultando as opiniões dos sujeitos. C. Coutinho (2008:7) considera poder "afirmar-se que o paradigma qualitativo pretende substituir as noções de explicação, previsão e controlo do paradigma quantitativo pelas de compreensão, significado e acção em que se procura penetrar no mundo pessoal dos sujeitos". Neste sentido perspetivamos a compreensão das representações dos trabalhadores para uma definição conjunta e participada dos objetivos para que a avaliação de desempenho seja pensada por (e para) os trabalhadores.

De igual modo, optamos por um estudo de caso - a valência de creche e jardín de infância de uma organização do terceiro setor - e como técnica de investigação o focus-group. Esta técnica foi escolhida pelo facto de os "grupos de discussão que dialogam sobre um tema em particular, receberem estímulos apropriados para o debate. Essa técnica distingue-se por suas características próprias, principalmente pelo processo de interação grupal" (Ressel et al, 2008:780). Neste sentido foram constituídos dois grupos, com uma dimensão bastante ampla:

Grupo 1: 12 trabalhadoras afetas à Creche (3 Educadoras de infância; 6 Ajudantes da ação educativa; 3 Trabalhadoras de serviços gerais);

Grupo 2: 13 trabalhadoras afetas ao Jardim de Infância (3 Educadoras de infância; 4 Ajudantes da ação educativa; 5 Trabalhadoras de serviços gerais; 1 Assistente administrativa).

\section{Apresentação e Análise dos dados}

No ámbito dos dois grupos, foi desenvolvido o focusgroup. Numa primeira fase, procuramos conhecer as representações destes atores sobre os conceitos alusivos à avaliação de desempenho e ainda vantagens e desvantagens. Assim, levamos para a sessão cartões com as palavras: Oportunidade; Medir; Reconhecer; Justiça; Injustiça; Diferenciar; Ameaça; Desempenho; Competência; Esforço; Dedicação; Aprendizagem; Melhoria; Acompanhamento; Autoridade. Posto isto, e após discussão e registo em notas de campo das diferentes opiniões, seguem-se os quadros com os resultados dos dois grupos de trabalhadores:

\begin{tabular}{|c|c|}
\hline Grupo 1 & Grupo 2 \\
\hline 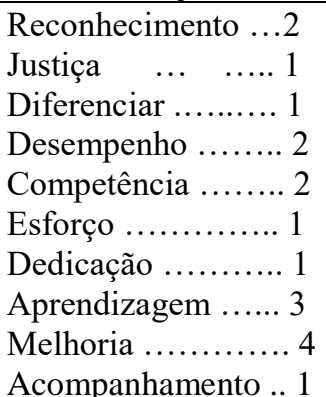 & $\begin{array}{l}\text { Oportunidade..... } 1 \\
\text { Medir ............. } 1 \\
\text { Reconhecimento ...1 } \\
\text { Justiça ............ } 4 \\
\text { Desempenho ...... } 3 \\
\text { Competência ...... } 2 \\
\text { Esforço ............ } \\
\text { Aprendizagem ... } 1 \\
\text { Melhoria ............ } 1\end{array}$ \\
\hline
\end{tabular}

Quadro 1 - Resultados da atividade de conceitos de AD (adaptado, Barbosa, 2016:52).

A palavra melhoria e justiça foram as que mais se destacaram sendo escolhidas cinco vezes. Os participantes justificam esta escolha pela melhoria dos serviços e das relações interpessoais entre colegas e entre o colaborador e a instituição que poderá advir do 
desenvolvimento da avaliação de desempenho. O desempenho foi enunciado cinco vezes uma vez que será a palavra-chave durante todo o processo. Por outro lado, também a competência foi uma palavra muito discutida, uma vez que consideram que será esta que fará a diferença entre os níveis de desempenho. Ainda a aprendizagem foi considerada pelos participantes quatro vezes que estas advêm do sistema de avaliação de desempenho.

As escolhas dos formandos revelam representações mais técnicas, mais direcionadas para as funções do posto de trabalho, perspetivam melhorias ao nível do serviço alinhadas no desempenho e na competência. As caraterísticas discutidas pelos grupos vão de encontro com a perspetiva de I. Chiavenato que considera "A avaliação de desempenho está totalmente voltada para a melhoria. O sistema de avaliação serve como importante ferramenta gerencial para melhorar o desempenho das pessoas, alavancar sua satisfação, melhorar o contexto de trabalho e a qualidade de vida das pessoas e proporcionar melhores resultados em termos de eficiência e eficácia" (1992:195). O autor considera ainda a avaliação de desempenho como "uma sistemática apreciação do desempenho do indivíduo no cargo e de seu potencial de desenvolvimento. Toda a avaliação é um processo para estimar ou julgar o valor, a excelência, as qualidades de alguma pessoa" (1989:85).

Após a abordagem dos conceitos seguiu-se a temática dedicada às vantagens e desvantagens da avaliação de desempenho.

Sobre a os pressupostos relativos às vantagens e desvantagens da avaliação de desempenho, I. Chiavenato entende que a "avaliação de desempenho tem despertado opiniões contraditórias" (1992:196) sendo que existem perceções extremamente favoráveis e outras completamente o oposto. Deste modo, deverão ser tidas em consideração certos cuidados, nomeadamente, "a avaliação de desempenho não pode restringir-se ao simples julgamento superficial e unilateral" (ibidem) mas deve ser "um processo dinâmico, bidirecional, interativo e, sobretudo, criativo através do qual gerente e subordinado interagem no sentido de criar condições para uma constante melhoria do desempenho, das tarefas, da qualidade de vida e, consequentemente, do melhor alcance dos objetivos organizacionais e individuais" (ibidem)

Após a discussão através do focus group, e registo em notas de campo segue-se o quadro síntese com as vantagens e desvantagens enunciadas pelos formandos oralmente:

\section{Grupo 2 \\ Grupo 2}

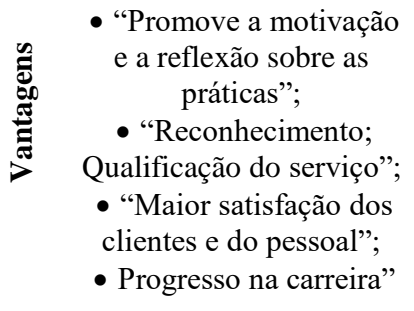

- "Tomar consciência

do desempenho e das suas práticas"

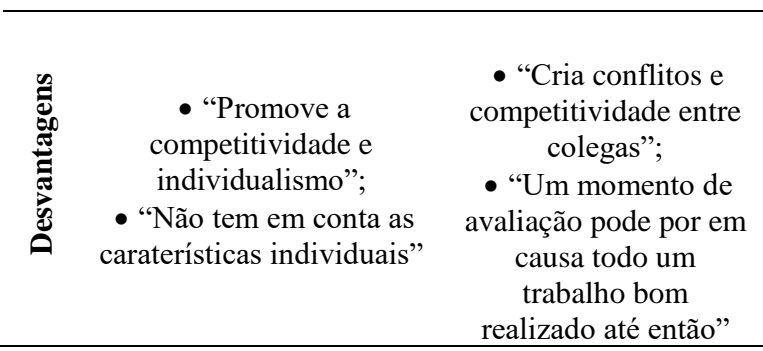

Quadro 2 - Resultados atividade vantagens e desvantagens da AD (ibidem:54).

Os argumentos foram diversificados. Deste modo segue-se uma síntese dos argumentos apresentados registados em notas de campo:

$$
\text { Argumentos favoráveis }
$$

- "É unânime que a avaliação de desempenho pode não ser $100 \%$ justa mas a auto avaliação permitirá uma aproximação maior à realidade”

- Poderá promover o espírito de grupo uma vez que as pessoas irão refletir mais vezes sobre o seu comportamento e irão melhorar as suas práticas mesmo no que respeito à relação com as colegas" Quadro 3 - Argumentos apresentados a favor da AD (ibidem:55).

Ainda que tenha sido unânime a ideia de que a avaliação de desempenho dificilmente será absolutamente justa, os participantes enalteceram a auto avaliação como forma de participarem no processo de atribuição de um nível de desempenho, fazendo assim valer dos seus argumentos. Também A. Caetano (1990:89) entende que a auto avaliação "revela diversas vantagens, salientando-se a participação e o envolvimento do subordinado nos processos organizacionais, a maior satisfação, quer do subordinado quer do chefe, e a melhoria do desempenho". Neste sentido é importante reforçar a ideia de que a avaliação de desempenho deve, efetivamente, ser um processo participativo de modo a que todos possam ter as mesmas oportunidades com vista à democracia no seio das organizações e fomentar a cidadania organizacional tal como C. Estevão (2001:186) refere no campo da formação. 


\begin{abstract}
Argumentos desfavoráveis
- "A avaliação não é 100\% justa"

- "Os clubismos, as amizades e a subjetividade inerente podem influenciar os resultados da AD";

- "O próprio avaliador poderá sentir dificuldades em construir objetivos mensuráveis e a proceder à avaliação de desempenho de uma colega próxima";

- "Receiam que não haja imparcialidade no processo avaliativo e que os avaliadores e/ou superiores vejam este processo como algo punitivo"

Quadro 4 - Argumentos apresentados contra a $\mathrm{AD}$ (ibidem:55).
\end{abstract}

Aquando da discussão acerca do lado negativo e dos problemas associados à avaliação de desempenho, uma vez mais foi abordada a questão da justiça e os receios em relação ao modo como os avaliadores encaram todo o processo. J. Rocha enumera também alguns dos problemas apresentados e classifica "as fontes dos problemas do processo de avaliação, da seguinte forma: Julgamento humano; avaliadores; proceso, política da organização; requisitos legais; inflexibilidade do método" (1997:126).

No final da sessão questionamos, um a um, sobre a opção de escolha entre ser e não ser avaliado. Das vinte e cinco participantes somente duas optariam por não serem avaliadas uma vez que, na opinião das mesmas, os receios em relação à avaliação de desempenho não se sobrepõem às vantagens que esta poderá trazer.

\section{Conclusão}

O sistema de avaliação de desempenho é um processo complexo e no focus-group que realizamos na investigação os participantes demonstraram interesse neste processo destacando a melhoria dos serviços e o feedback que pode ser obtido em relação aos seus desempenhos. No que respeita ao feedback das suas práticas por parte da instituição, os participantes perspetivam a avaliação como um fator primordial na motivação e melhoria das suas práticas no desenvolvimento do seu trabalho. Neste sentido, é crucial que os trabalhadores participem ativamente nestes processos quer o nível da definição de objetivos quer ao nível de metodologías de auto-avaliação. Contudo, J. Rocha (1997:129) refere que "a generalidade das empresas em Portugal usa processos de avaliação, sem qualquer participação dos avaliados”, o que na visão do autor pode trazer consequências negativas uma vez que pode surtir efeitos contraditórios aqueles que se espera com a avaliação de desempenho. Assim, o autor reforça a ideia que "a questão básica em qualquer processo de avaliação é a seguinte: os empregados devem conhecer o que é esperado deles e como deverão fazer para alcançar esses objectivos" (ibidem). Os nossos dados vão precisamente ao encontro da perspetiva do autor pois não é possível perspetivarmos a democracia e cidadania organizacional sem que haja esclarecimento, participação e auto-avaliação, como os participantes da nossa investigação defendem. Os dados da investigação evidenciam que as representações dos trabalhadores acerca da avaliação de desempenho direcionam-se no sentido de que este mecanismo pode contribuir para o desenvolvimento pessoal e profissional dos trabalhadores mas também para o desenvolvimento organizacional, apesar de se registarem nos trabalhadores alguns receios em torno desta problemática, nomeadamente quanto à forma como será encarada pelos superiores hierárquicos, podendo ser um instrumento de ameaça e/ou punição. Ainda que tenha sido unânime nos dois grupos a ideia de que a avaliação de desempenho dificilmente seja absolutamente justa, os atores elegeram a auto avaliação como forma de participarem no processo de atribuição do nível de desempenho, democratizando as organizações.

\section{Bibliografia}

Barbosa, A. (2016). Avaliação de Desempenho: Dilemas e desafios. Braga: Universidade do Minho.

Brandão, A. \& Parente, C. (1998). Configurações da função Pessoal. As especificidades do caso português. Revista Organizações e Trabalho, no 20, 1998, p. 2340.

Caetano, A. (1990). Avaliação de Desempenho Metáforas, Conceitos e Práticas. Lisboa: RH Editora.

Chiavenato, I. (1989). Recursos Humanos na Empresa. Volume 3. São Paulo: Editora Atlas.

Chizzotti, A. (2001). Pesquisa em Ciência Humanas e Sociais. São Paulo: Cortez Editora.

Coutinho, C. (2008). A qualidade da pesquisa educativa de natureza qualitativa: questões relativas à fidelidade e validade. Revista Educação Unisinos, 12(1), 5-15.

Estevão, C. (2001). Formação, gestão, trabalho e cidadania: Contributos para uma sociologia crítica da formação. Educação \& Sociedade, ano XXII, no 77.

Levy-Leboyer, C. (1991). Avaliação do Pessoal na Empresa. Lisboa: Editora Presença.

Pontes, B. (1999). Avaliação de desempenho - nova abordagem. 8.ed. São Paulo: LTr.

Ressel, L.; Beck, C.; Gualda, D.; Hoffmann I.; Silva, R. e Sehnem, G. (2008). O Uso Do Grupo Focal Em Pesquisa Qualitativa. In Contexto Enferm, Florianópolis, pp. 779- 78.

Rocha, J. (1997). Gestão de Recursos Humanos. Lisboa: Editorial Presença.

Legislação:

Lei n. ${ }^{\circ}$ 66-B/2007 de 28 de dezembro

Lei n. ${ }^{\circ}$ 27/2014 de 8 de maio 